Hydraulic Engineering Repository

Ein Service der Bundesanstalt für Wasserbau

Nielsen, A. W.; Sumer, B. Mutlu; Fredsoe, J.; Christensen, E. D.

Scour Protection Around Offshore Wind Turbines. Monopiles

Verfügbar unter / Available at:

https://hdl.handle.net/20.500.11970/100314

Vorgeschlagene Zitierweise / Suggested citation:

Nielsen, A. W.; Sumer, B. Mutlu; Fredsoe, J.; Christensen, E. D. (2010): Scour Protection Around Offshore Wind Turbines. Monopiles. In: Burns, Susan E.; Bhatia, Shobha K.; Avila, Catherine M. C.; Hunt, Beatrice E. (Hg.): Proceedings 5th International Conference on Scour and Erosion (ICSE-5), November 7-10, 2010, San Francisco, USA. Reston, Va.: American Society of Civil Engineers. S. 440-449. 


\title{
Scour Protection Around Offshore Wind Turbines. Monopiles
}

\author{
A. W. Nielsen ${ }^{1}$, B. M. Sumer ${ }^{2}$, J. Fredsøe ${ }^{3}$ and E. D. Christensen ${ }^{4}$
}

I Technical University of Denmark, DTU Mekanik, Section of Coastal, Maritime and Structural Engineering, Building 403, 2800 Kgs. Lyngby, Denmark; e-mail: awni@mek.dtu.dk

2 Technical University of Denmark, DTU Mekanik, Section of Coastal, Maritime and Structural Engineering, Building 403, 2800 Kgs. Lyngby, Denmark; e-mail: bms@mek.dtu.dk

${ }^{3}$ Technical University of Denmark, DTU Mekanik, Section of Coastal, Maritime and Structural Engineering, Building 403, 2800 Kgs. Lyngby, Denmark; e-mail: jf@mek.dtu.dk

${ }^{4}$ DHI, Agern Allé 5, 2970 Hørsholm, Denmark; e-mail: edc@dhigroup.com

\section{ABSTRACT}

The flow processes in a scour protection around a mono-pile in steady current is described in relation to transport of sediment in the scour protection based on physical model tests. Transport of sediment in the scour protection may cause sinking of the scour protection. This may reduce the stability of the mono-pile and change for instance the natural frequency of the dynamic response of an offshore wind turbine in an unfavorable manner. The most important flow process with regard to transport of sediment and sinking of the scour protection is found to be the horseshoe vortex.

It is found that a larger pile diameter relative to the size of the protection stones will cause a larger sinking and that two layers of stones will decrease the sinking relative to one layer of stones with the same size.

\section{INTRODUCTION}

During the last decade more and more wind farms have been erected offshore. One of the first larger offshore wind farms is the Horns Rev I. The Horns Rev I is located in relatively shallow water (6.5 to $13 \mathrm{~m}$ water (MSL)) about $20 \mathrm{~km}$ off the Danish West Coast in the North Sea. This area is exposed to strong tidal currents and large waves from the North Sea. The wind turbines are founded on mono-piles with a scour protection made of a two-layer cover (quarry run from around $350 \mathrm{~mm}$ to $550 \mathrm{~mm}$ ) and a $0.5 \mathrm{~m}$ thick filter layer (sea stones from around 30 $\mathrm{mm}$ to $200 \mathrm{~mm}$ ) between the armor layer and the seabed. The wind farm was installed in the summer 2002. A control survey in 2005 showed that the scour protections adjacent to the mono-piles sank up to $1.5 \mathrm{~m}$. This was unexpected and 
shortly after the survey in 2005 the holes were repaired by adding additional stones.

Scour around unprotected piles have been studied extensively over the last decades. Most of the available results are compiled in Breusers and Raudkivi (1991), Hoffmans and Verheij (1997), Melville and Coleman (2000) (mostly river application), Whitehouse (1998) and Sumer and Fredsøe (2002) (mostly marine application). Scour protection of piles has not been studied nearly as much and the mechanism of failure of scour protections around a mono-pile has only been described briefly. In order to gain an understanding of the mechanisms that cause the sinking of the scour protection, an extensive program of physical model tests with steady current has been carried out in the present study, in an attempt to contribute to the knowledge obtained recently by Chiew and Lim (2000), Lauchlan and Melville (2001), Chiew (2002), De Vos (2008) among others. The model tests showed that the horseshoe vortex, the key element to cause scour around unprotected piles, see e.g. Dargahi (1989) and Roulund et al. (2005), is a key flow feature governing the sinking process.

\section{EXPERIMENTAL SETUP}

The tests were conducted in two different current flumes. (1) A $2 \mathrm{~m}$ wide, 23 $\mathrm{m}$ long (excluding in- and outlet sections) and $0.5 \mathrm{~m}$ deep flume; and (2) a $4 \mathrm{~m}$ wide, $28 \mathrm{~m}$ long (excluding in- and outlet sections) and $1.0 \mathrm{~m}$ deep flume. The flumes were equipped with recirculation pumps providing mean current speeds of more than $60 \mathrm{~cm} / \mathrm{s}$ in the actual setups. Two different setups were used for the tests in the $2 \mathrm{~m}$ wide flume: A fixed bottom setup used for flow visualizations and velocity profiles measurements, and a live-bed test setup with a $10 \mathrm{~m}$ long and $0.15 \mathrm{~m}$ deep sand section, see Figure 1. The ramps towards the sand section were made of smooth plywood plates. In the case of the $4 \mathrm{~m}$ wide flume only live-bed tests were conducted. The sand section was around $10 \mathrm{~m}$ long and $0.35 \mathrm{~m}$ deep. The ramp from the actual bottom to the sand section was $3 \mathrm{~m}$ long with a core of concrete blocks covered with at least one layer of stones $\left(d_{50}=4 \mathrm{~cm}\right)$, see Figure 2. In some of the tests in the $4 \mathrm{~m}$ wide flume, two piles were tested at the same time, in order to save time. The piles were placed at the same distance from the inlet and the distance between the piles was $1.75 \mathrm{~m}$, which was large enough to ensure no interference.

In the case of the fixed-bottom experiments an approximately $0.5 \mathrm{~cm}$ thick, $2.9 \mathrm{~m}$ long, white plastic plate, with $15 \mathrm{~cm}$ long tapered upstream edge, was placed on the base bottom over the entire width of the flume enabling a good contrast for the flow visualizations. For the velocity profile measurements (using Laser Doppler Anemometry, LDA) the plate was painted matte black to reduce reflections of the laser beams. The pile was placed $2.0 \mathrm{~m}$ downstream of the upstream edge of the plastic plate (approximately $15 \mathrm{~m}$ from the inlet section). 


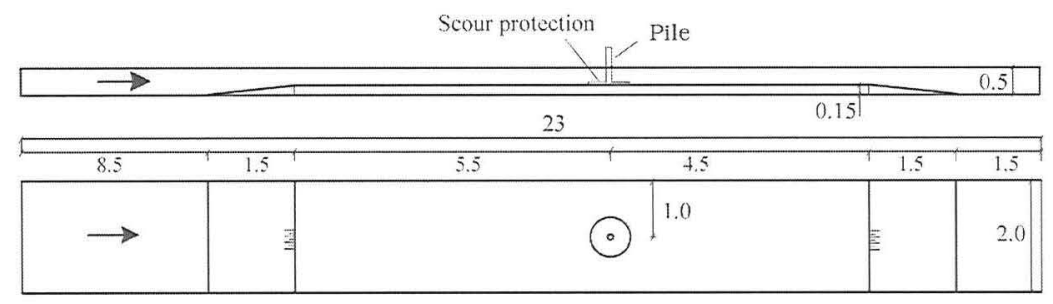

Figure 1 Setup for the $2 \mathrm{~m}$ wide flume.

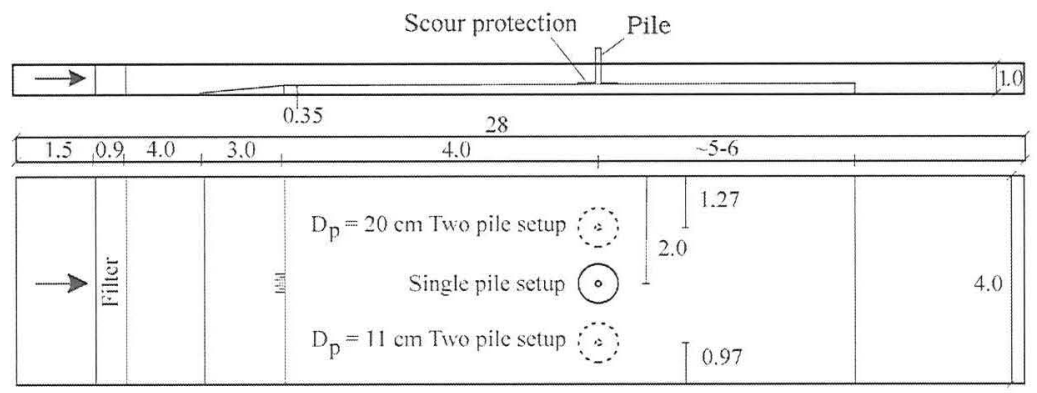

Figure 2 Setups for the $4 \mathrm{~m}$ wide flume.

In all setups the bottom end of the piles were closed by an end plate to ensure that the bottom of the pile was completely sealed.

The flow velocity was measured in two different ways: A small propeller ( 3 $\mathrm{cm}$ in diameter) was used in the case of the live-bed tests and a submerged pen size LDA probe was used in the case of the fixed-bottom velocity profiles measurements. The pen-size LDA probe was a two component probe, approximately $1 \mathrm{~cm}$ in diameter and $15 \mathrm{~cm}$ long. It had a focal length of $80 \mathrm{~mm}$ (in water), a beam spacing of $8 \mathrm{~mm}$ and a beam diameter of $0.27 \mathrm{~mm}$. The probe was placed vertically pointing downwards, when used to measure velocities in between the stones and placed horizontally when used outside the stones.

The sinking of the stones was determined by measuring the vertical displacement of the stones adjacent to the pile. To avoid disturbances due to the irregularities of the stones the sinking was measured with reference to the same point marked on the stone. In case of large rotations or if the stone was covered by other stones the measuring of the sinking of that stone was disregarded. In the case when a disregarded stone was likely to be the stone with maximum sinking the entire test was disregarded. Based on the results of the tests it was found that the maximum sinking always occurred for the stone upstream of the pile or on the sides 
of the pile (stone positions 1, 2, 3, 7 and 8 in Figure 3). The number of stones where the sinking was measured around the pile was between three and eight for each test. In the case of only three stones were measured, these were 1,3 and 7.

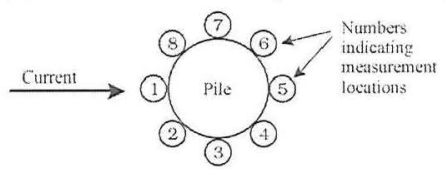

Figure 3 Position of the stones used for measuring the sinking of the scour protection.

Along with the sinking of the stone adjacent to the pile, the scouring and deposition of sand in the area around the pile was measured using measuring pins (3 $\mathrm{mm}$ in diameter) with scales in the form of colored strips. The pins were placed in and around the scour protection.

\section{TEST CONDITIONS}

One sand size was used for the experiments, $d_{50}=0.18 \mathrm{~mm}$. The pile diameter, $D_{p}$, was changed in the interval $7.5 \mathrm{~cm}$ to $20.0 \mathrm{~cm}$. The extent of the scour protection, $w_{\text {cover }}$, was kept in the interval of 20 to $90 \mathrm{~cm}$ giving a relative extension of the scour protection, $w_{\text {cover }} / D_{p}$, of 2.0 to 4.5 , in which $w_{\text {cover }}$ is the plan-view extension of the scour protection from upstream edge to downstream edge. The size of the cover stones, $D_{\text {cover }}$, was in the interval $1.9 \mathrm{~cm}$ to $10.3 \mathrm{~cm}\left(d_{50}\right)$ and applied in one to three layers. The water depth, $h$, was maintained at $29 \mathrm{~cm}$ to $30 \mathrm{~cm}$ and at $56 \mathrm{~cm}$, giving a relative water depth, $h / D_{p}$, of 2.1 to 5.1. The velocity, $U_{D / 2}$, at half the pile diameter above the bottom was kept within the interval $35 \mathrm{~cm} / \mathrm{s}$ to $55 \mathrm{~cm} / \mathrm{s}$ giving a Shield parameter from 0.10 to 0.23 in which $\theta$ is defined as:

$$
\theta=\frac{U_{f}^{2}}{g(s-1) d_{50}}
$$

where $U_{f}$, the friction velocity associated with the far field, is calculated using the Colebrook-White equation.

Three different materials were used for the scour protection: Round stones with a mean diameter $\left(d_{50}\right)$ of $D_{\text {cover }}=10.3 \mathrm{~cm}$ with $d_{15}=9.0 \mathrm{~cm}$ and $d_{85}=11.2 \mathrm{~cm}$, The stones were used in one layer with a mean thickness of $7.6 \mathrm{~cm}$; crushed stones with mean diameter of $D_{\text {cover }}=4.3 \mathrm{~cm}$ with $d_{15}=3.7 \mathrm{~cm}$ and $d_{85}=4.9 \mathrm{~cm}$ and, the stones were used in one, two and three layers with a mean thickness of $3.2,6.2$ and $9.0 \mathrm{~cm}$, respectively; crushed stones $D_{\text {cover }}=1.9 \mathrm{~cm}$ with $d_{15}=1.6 \mathrm{~cm}$ and $d_{85}=2.8 \mathrm{~cm}$, the stones were used in one and two layers with a mean thickness of 1.8 and $3.3 \mathrm{~cm}$, respectively. 


\section{RESULTS}

\section{Fixed-Bed Results}

The flow around/in the scour protection around the monopile has been investigated using flow visualization and velocity measurements (LDA). The flow visualizations were made by adding blue and green dye at the edge of the scour protection and in between the stones adjacent to the upstream side of the pile. Only one layer of $4 \mathrm{~cm}$ stones was used in order not to block the view of the flow near the base bottom and to keep the overall view relatively simple.

The flow visualizations showed that flow pattern around the monopile is very similar to the pattern around an unprotected monopile. The flow around an unprotected pile has been studied extensively and the results are compiled in for example Sumer and Fredsøe (2002). In relation to scour development the most important flow feature is the horseshoe vortex, see for example Baker (1979) and (1985), Niedoroda and Dalton (1982), Dargahi (1989) and Roulund et al. (2005).

The present flow visualization showed that the horseshoe vortex is still the main reason for the removal of sediment close to the upstream side of the pile, see Figure 4: When adding dye at the top of the stones adjacent to the upstream side of the pile, the dye was transported down into the stones and then upstream in between the stones. Around 10 to $15 \mathrm{~cm}$ from the upstream edge of the pile and 10 to $15 \mathrm{~cm}$ from the upstream edge of the scour protection these two, opposite directed flows met at a separation line. At the separation line they were forced upwards into the main flow and transported away.

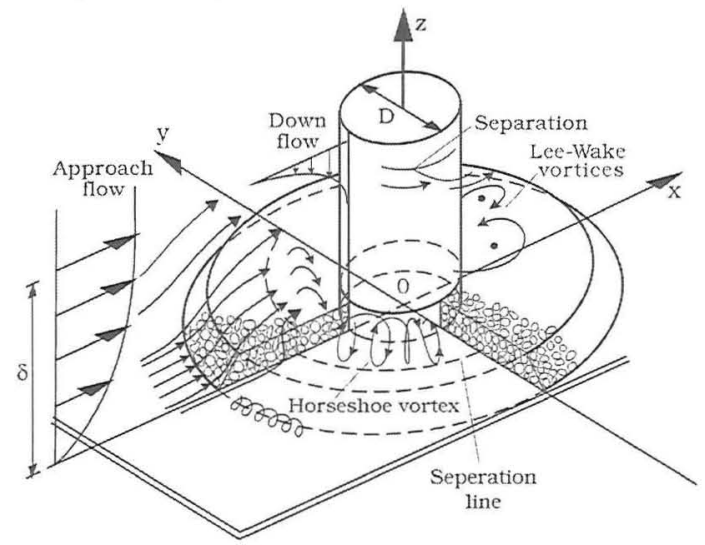

Figure 4 Sketch of the flow around a mono-pile with scour protection.

By adding dye at the upstream edge of the scour protection two important flow patterns were observed: Small horseshoe vortices were generated in front of the 
protection stones (as sketched in Figure 4) while water was able to flow into the scour protection in the gaps between the stones.

Flow visualizations were made at different position at the side of the pile and downstream of the pile. These flow visualizations showed no important flow features in relation to the sinking of the scour protection. The flow at the side of the pile was dominated by the downstream part of the horseshoe vortex. A flow into the scour protection at the downstream edge of the scour protection was observed, but this flow was weak and it has not been possible to relate it to any important effect in relation to the sinking of the scour protection. The most important flow feature at the downstream side of the cylinder is the vortex shedding, see Figure 4. The live-bed tests showed that the vortex shedding was not causing any significant sinking, however.

Velocity profiles in between the stones have been measured from approximately $1.5 \mathrm{~cm}$ above the base bottom to the surface using LDA. The reason for the relatively large distance from the base bottom to the lowest measuring point was that the LDA probe needed to be vertical in order to measure in between the stones. This caused some heavy reflections from the base bottom which made it impossible to measure closer to the bottom with the available equipment.

The velocity profiles upstream of the pile are shown in Figure 5. It is clearly seen that a significant return flow is present in between the stones up to around 10 $\mathrm{cm}$ from the edge of the pile. This is consists very well with the results of the flow visualizations.

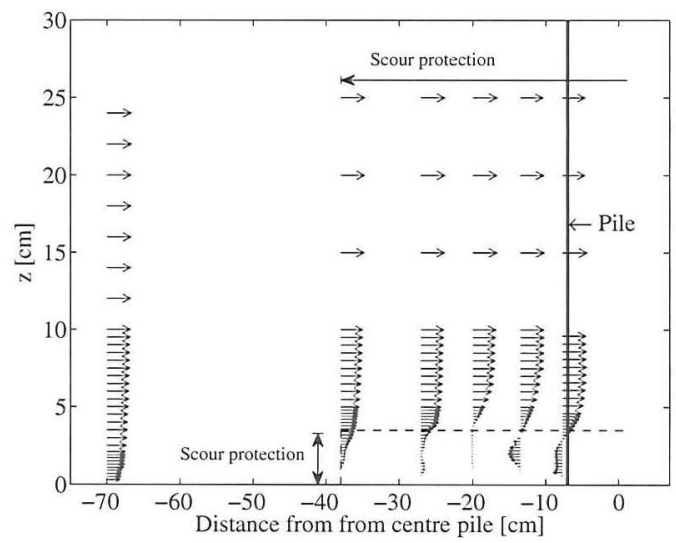

Figure 5 Velocity profiles at different distances to the mono-pile with one layer of $4 \mathrm{~cm}$ stones. The undisturbed velocity is $40 \mathrm{~cm} / \mathrm{s}$. 
As mentioned previously, small horseshoe vortices were observed in front of the protection stones at the upstream side of the scour protection. This will, combined with the inflow in the gaps between the stones, cause edge scour. However, edge scour is not a problem as long as the scour protection is large enough and contain enough material. With the edge scour, the stones will slump down into the scour hole and form a protective slope.

The flow into the scour protection at the downstream side of the pile is very weak and is not able to carry any significant amount of sediment. The sediment bed tests showed a significant deposition of sediment in between the stone in the wake of the pile and only very little or no sinking at all at the downstream edge of the pile, contrary to the case of an unprotected pile, where the vortex shedding is responsible for the scour at the downstream side of the pile, see e.g. Sumer and Fredsøe (2002).

\section{Live-Bed Results}

The live-bed tests showed a clear correlation between the sinking of the scour protection, the stone size, the thickness of the scour protection and the pile diameter. The flow visualizations showed that the horseshoe vortex penetrated into the scour protection.

Based on the results of the flow visualizations and the velocity measurements the flow pattern around the pile causing the sinking of the scour protection can be described as follows: The horseshoe vortex caused by the pile penetrates into the scour protection and causes scouring adjacent to the upstream side of the pile. The scoured material is transported by the horseshoe vortex either upstream to the separation line or to the sides. The material will in both cases be deposited in between the stones, relatively far from the pile or, if the horseshoe vortex is strong enough, sucked/winnowed up into to the main body of the flow and transported downstream. The reason for the suction/winnowing of the sand out from the scour protection is a combination of suction by the main flow, as described in Sumer et al. (2001), and the upward directed flow at the separation line between the incoming flow and the horseshoe vortex. The tests have shown that the deposition inside the scour protection is very limited on the upstream side of the pile, and for this reason most of the sediment must be sucked out from the scour protection and transported away. Sumer et al. 2001 used the parameter e/Dstone as the non-dimensional parameter for the sinking of an undisturbed protection layer. The process for a scour protection around a pile is in many ways similar to that described above and the parameter $e / D_{\text {cover }}$ is also adopted for the present process as well.

The size and strength of the horseshoe vortex is determined by the flow velocity and the pile size. The velocity is indirectly included in the Shields parameter, while the pile diameter is not included in any of the other parameters 
above. The horseshoe vortex causes the removal of the sediment and a larger pile/horseshoe vortex will, in absolute terms, cause a larger sinking. On the other hand, for a given pile diameter, the larger the ratio $D_{p} / D_{\text {cover, }}$, the larger the penetration of the agitating forces. Therefore the sinking, $e_{\max } / D_{\text {cover }}$, should be larger for larger values of $D_{p} / D_{\text {cover. }}$. If the ratio $D_{p} / D_{\text {cover }}=0$ the situation is the undisturbed protection, Sumer et al. (2001). In this case Sumer et al. (2001) showed that the ratio $e_{\max } / D_{\text {cover }}=0.1$ for one layer of stones, in agreement with the trend seen in Figure 6.

Figure 6 shows the non-dimensional sinking relative to the non-dimensional pile size for $0.06<\theta<0.20$. There is a clear trend that the larger the pile diameter, the larger the sinking. This is obviously linked to the horseshoe vortex; the larger the pile diameter, the larger the horseshoe vortex, and the larger the scour underneath the stones, and therefore the larger sinking. The sinking decreases for increasing number of layers. When the number of layers is increased from one to two the sinking is decreased with around a factor of two for $D_{p} / D_{\text {cover }}$ smaller than around 5 , however, the effect is much smaller for $D_{p} / D_{\text {cover }}=10$. There have only been made one test with three layers and considering the scatter of the results with one and two layers it is not clear if the third layer provide any significant extra protection.

Regarding the scatter in the data in Figure 6, this may be attributed to the way in which the stones are laid around the model pile, considering the fact that the stone size in the tests was relatively large.

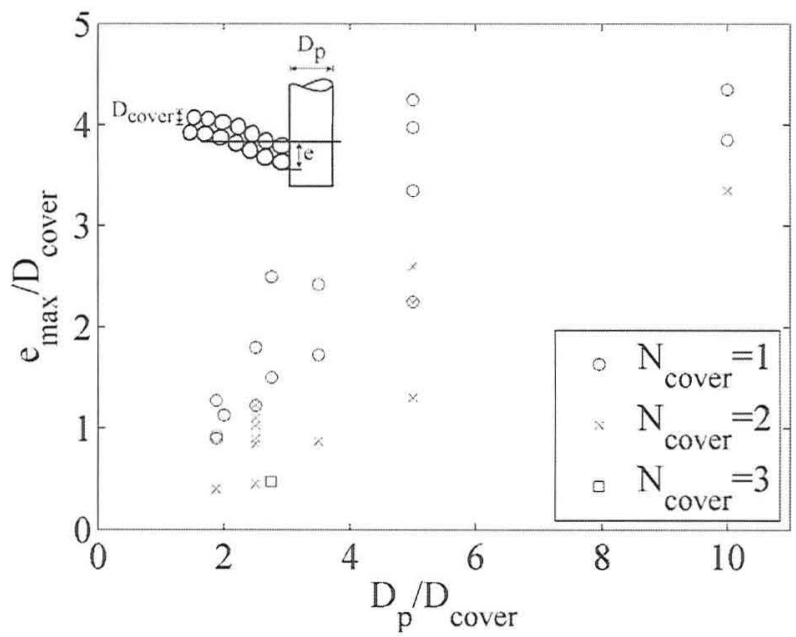

Figure 6 Results of the live-bed tests. The the range of $\theta$ is $0.10<\theta<0.23$ and that of $h / D_{p}$ is $1.5 \leq h / D_{p} \leq 5.1$. 


\section{CONCLUSION}

The mechanism causing sinking of the scour protection adjacent to the mono-pile has been identified as the horseshoe vortex penetrating into the scour protection. When the horseshoe vortex penetrates into the scour protection it transport the sediment adjacent to the pile upstream, where it is winnowed and transported away by the main flow.

- It is found that a larger pile diameter relative to the size of the protection stones will cause a larger sinking. The maximum sinking is found to be approximately 4 to 4.5 times the diameter of the cover stones in case of one layer of stones and approximately 3 to 3.5 in case of two layers of stones.

- Two layers of stones will decrease the sinking relative to one layer of stones with the same size. For values of $D_{p} / D_{\text {cover }}$ smaller than approximately 5 the sinking seems to be reduced by a factor of two if the number of layers is increase from one to two.

\section{ACKNOWLEDGEMENT}

This research was carried out as part of the Statkraft Ocean Energy Research Program, sponsored by Statkraft (www.statkraft.no). The study was partially supported by the Danish Council for Strategic Research (DSF)/Energy and Environment under the program Seabed Wind Farm Interaction (http:/sbwi.dhigroup.com, sagsnr. 2104-07-0010) and DHI (www.dhigroup.com). The fixed-bottom experiments and a major part of the live-bed experiments were conducted by MSc Adriana Hudecz. A part of the live-bed experiments were conducted by François Roignant.

\section{REFERENCES}

Baker, C.J. (1979). "The laminar horseshoe vortex". J. Fluid Mechanics, vol. 95, part 2, 347-367

Baker C.J. (1985). "The position of points of maximum and minimum shear stress upstream of cylinders mounted normal to flat plates". J. Wind Eng. And Industrial Aerodyn., vol. 18, 263-274

Breusers H.N.C. and Raudkivi A.J. (1991). "Scouring- Hydraulic design considerations", A.A. Balkema.

Chiew, Y.M. and Lim, F.-H. (2000). "Failure behaivior of riprap layer at bridge piers under live-bed conditions". J. Hydraulic Eng. Vol. 126, No. 1, 43-55.

Chiew Y.M. (2002). "Failiure mechanisme of riprap layer around bridge piers. Proc., First Int. Conf. on Scour of Foundations", H.-C. Chen and J.-L. Briaud, eds., Stallion Press, Singapore, Vol. I, 70-92. 
Dargahi, B. (1989). "The turbulent flow field around a circular cylinder". Experiments in Fluids, vol. 8, 1-12.

De Vos, Leen (2008). “Optimisation of scour protection design for monopiles and quantification of wave run-up - Engineering the influence of an offshore wind turbine on local conditions". $\mathrm{PhD}$ Thesis, Dept. of Civil Engineering, University of Ghent, Ghent, Belgium.

Hoffmanns, G.J.C.M. and Verheij H.J. (1997). "Scour manual". A.A. Balkema.

Lachlan, C.S. and Melvile, B.W. (2001). "Riprap protection at bridge piers". J. Hydraulic Eng. Vol. 127 No. 5, 412-418.

Melville, B.W. and Coleman S.E. (2000). "Bridge Scour". Water Resources Publications, LLC, CO, USA, $550 \mathrm{p}$.

Niedoroda A.W. and Dalton C. (1982): "A review of the fluid mechanics of ocean scour", Ocean Engineering, vol. 9, No. 2, 150-170.

Roulund A., Sumer B.M., Fredsøe J. and Michelsen J. (2005). "Numerical and experimental investigation of flow and scour around a circular pile”, J. Fluid Mech., vol. 534, 351-401.

Sumer, B.M., Cokgor S. and Fredsøe J. (2001). "Suction of sediment from between armour blocks”. J. Hydraulic Engineering, ASCE, vol. 127, No. 4, 293-306.

Sumer B.M. and Fredsøe J. (2002). "The mechanics of scour in the marine environment", World Scientific.

Whitehouse R. (1998). "Scour at marine structures". Thomas Telford Publications. 